\title{
Synaptogenesis and Heritable Aspects of EXECUTIVE ATTENTION
}

\author{
John A. Fossella, ${ }^{1 *}$ Tobias Sommer, ${ }^{2}$ Jin Fan, ${ }^{1}$ Don Pfaff, ${ }^{3}$ and Michael I. Posner ${ }^{1}$ \\ ${ }^{1}$ Sackler Institute for Developmental Psychobiology, Weill Medical College of Cornell University, New York, New York \\ ${ }^{2}$ Cognitive Neuroscience Laboratory, Department of Neurology University of Hamburg, Germany \\ ${ }^{3}$ Laboratory of Neurobiology and Behavior Rockefeller University, New York, New York
}

In humans, changes in brain structure and function can be measured non-invasively during postnatal development. In animals, advanced optical imaging measures can track the formation of synapses during learning and behavior. With the recent progress in these technologies, it is appropriate to begin to assess how the physiological processes of synapse, circuit, and neural network formation relate to the process of cognitive development. Of particular interest is the development of executive function, which develops more gradually in humans. One approach that has shown promise is molecular genetics. The completion of the human genome project and the human genome diversity project make it straightforward to ask whether variation in a particular gene correlates with variation in behavior, brain structure, brain activity, or all of the above. Strategies that unify the wealth of biochemical knowledge pertaining to synapse formation with the functional measures of brain structure and activity may lead to new insights in developmental cognitive psychology. MRDD Research Reviews 2003;9:178-183.

Key Words: genetics; attention; synaptogenesis; development; cognition

\section{INTRODUCTION}

$\mathrm{I}$ $\mathrm{t}$ is well known that human performance on cognitive tasks requiring executive attention improves with age during the first ten years of life [Diamond, 1988; 1996: Flavell et al., 1966; Espy, 1999]. Developmental changes in the meso-cortical dopamine system are thought to underlie normal development of executive functions [Diamond, 1996]. Frequently, the cellular development of dopaminergic projections is cited as a possible explanation for this phenomenon. In macaques, for example, the 'A not B' task normally shows a sharp increase in performance during the first six months of life. Behavioral performance is paralleled by a post-natal increase in DA levels [GoldmanRakic, 1981] and an increase in DA receptor gene expression [Lidow MS et al., 1991]. In addition, tyrosine hydroxylase (TH)-positive processes in prefrontal areas 9 and 46 show a gradual maturation of axons and varicosities up until two to three years of age [Rosenberg and Lewis, 1995]. Such changes in cellular arborization suggest that dopaminergic synapse formation plays a role in the normal development of inhibitory control and executive attention. In humans, postnatal development proceeds with a period of synaptic overgrowth followed by a period of synaptic pruning near adolescence [Huttenlocher et al.,1982]. A relatively delayed period of synaptic and dendritic development occurs in the prefrontal cortex (PFC) [Huttenlocher,
1979; Conel, 1939]. While a delay in synaptogenesis and dendritic arborization in the PFC correlates with a relative delay in the onset of executive function, it is not clear how the regulation of synaptogenesis influences normal cognitive development.

\section{Suggestive Evidence Linking Disruptions in Synaptogenesis With Abnormal Cognitive Development}

More evidence implicates abnormal pre- and post-natal synaptogenic processes in disorders where executive function is diminshed or severely developmentally delayed. The most striking example is seen in fragile-X mental retardation (FMR). This genetic disorder [reviewed in Irwin et al., 2000; Hagerman, 1997] arises from the loss of function of a single gene that encodes the fragile- $X$ mental retardation protein (FMRP). This protein is locally translated in synaptic spines in response to neuronal stimulation [Weiler et al., 1997]. Golgi-histochemical studies of post-mortem tissue from patients with FMR show no gross anatomical disturbances, but rather abnormalities in the quantity and morphology of dendritic spines in pyramidal cells [Wisniewski et al., 1991]. An excess of dendritic spines in fragile $\mathrm{X}$ patients indicates a deficit in synaptic pruning. This pathology is also seen in mice that are deficient in FMRP whose pyramidal neurons show an excess of spines [Kooy et al., 1996]. Other forms of mental retardation seem to implicate synaptogenesis as a key step in cognitive development. Mutations in the rho-family of small GTPases which are key regulators of synaptogenesis are implicated in mental retardation syndromes. oligophrenin-1, a rho activator, has been associated with X-linked mental retardation, and synaptojanin, a rho-family effector, is overexpressed in Down's syndrome [Billuart et al., 1998; Arai et al., 2002].

Schizophrenia is another developmental disorder where many independent lines of evidence point to abnormalities in the process of synapse formation. Glucose utilization and blood

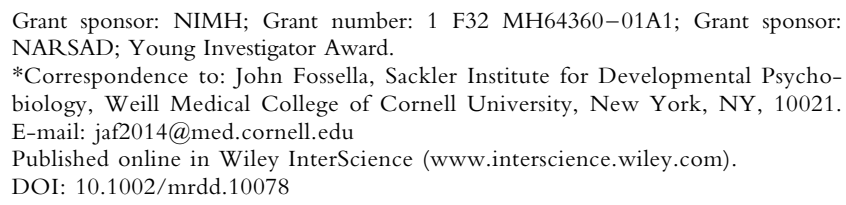

Grant sponsor: NIMH; Grant number: 1 F32 MH64360-01A1; Grant sponsor: NARSAD; Young Investigator Award.

*Correspondence to: John Fossella, Sackler Institute for Developmental Psychobiology, Weill Medical College of Cornell University, New York, NY, 10021. E-mail: jaf2014@med.cornell.edu

Published online in Wiley InterScience (www.interscience.wiley.com). DOI: $10.1002 / \operatorname{mrdd} .10078$ 
flow measures of patients with schizophrenia reveal diminished function of the frontal cortex [Goldman-Rakic and Selemon, 1997; Andreasen et al., 1992; Weinberger er al., 1986; Park and Holzman, 1992]. Gene expression measures on post-mortem brain tissue from patients with schizophrenia show that many genes involved in pre- and post-synaptic regulation of synapse function are differentially expressed in the pre-frontal cortex [Mirnics et al., 2000; Vawter et al., 2002; Hakak et al., 2001; Hemby et al., 2002]. A loss of synaptogenic gene function may be related to decreases in dendritic spine density in prefrontal cortex layers 3 and 4 [Glantz and Lewis, 2000]. Interestingly, some of the downregulated genes, such as nsf and vacuolar ATPase are directly involved in energy consumption via ATP hydrolysis and thus may contribute to the diminished metabolism of the PFC seen in schizophrenia. Further evidence of disruption of normal synaptogenic processes can be found in longitudinal brain structure studies of patients with early onset schizophrenia. An accelerated loss of grey matter seems to appear early in parietal areas and spreads through adolescence to temporal and frontal areas [Thompson et al., 2001]. A loss of grey matter may be related to decreases in input from the mediodorsal thalamic nucleus, given the evidence for a decreased number of these neurons [Young et al., 2000] and reduced thalamic size [Andreasen et al., 1994]. Examinations of stress induced neuronal excitotoxicity in schizophrenia reveals more clues about mechanisms of synaptic loss. Dopaminergic innervation of interneurons in layers II and $\mathrm{V}$ appear to be increased in post mortem analyses of schizophrenia [Benes, 2000]. Under normal conditions, the synaptic contacts on local interneurons that utilize DRD2 receptors result in inhibition of cell activity [Nicola et al., 2000]. Such hyperinnervation of interneuronal DRD2 contacts is suspected to disable local inhibition of pyramidal cells and lead to excess glutamatergic signalling and excitotoxic damage in downstream brain areas.

\section{Cellular and Molecular Genetic Clues}

Ramon y Cajal was the first to identify dendritic "espinas" and to suggest that these were sites that allowed neurons to connect and exchange information [DeFelipe and Jones, 1988]. Current studies on synaptogenesis use similar histochemical Golgi-staining methods as well as new methods that allow the visualization and 3-D reconstruction of syn- apses and dendritic spine movements in vitro and in vivo. Many time-lapse digital videos showing the dynamic movements of developing synapses have been published on the world-wide-web [Bonhoeffer and Yuste, 2002]. In vivo studies using 2-photon laser scanning microscopy have shown that experience-dependent functional changes in the adult neocortex are associated with a continuous cycle of synapse loss and new synapse formation [Lendvai et al., 2000; Trachtenberg et al., 2002]. In humans, where microscopic approaches are not feasible, some indirect measures have been applied. PET studies that measure cerebral glucose utilization via labeled 2-deoxyglucose, have shown that the frontal cortex is delayed in glucose consumption during post-natal development and undergoes a rise and subsequent diminution

\section{"More evidence implicates abnormal pre- and post-natal synaptogenic processes in disorders where executive function is diminshed or severely developmentally delayed. The most striking example is seen in fragile-X mental retardation (FMR).'”}

of utilization around 10 years of age [Chugani, 1998]. These results are similar to the synapse counting results of Huttenlocher, although the direct relationship between glucose utilization and the metabolic demands of synaptogenesis and synaptic transmission may be complex [Chugani, 1998]. Some progress has been made using MRI-based brain morphometry [Thompson et al., 2001]. This technique has been evaluated in the context of cognitive development [Casey et al., 2000; Geidd et al., 1996] and in rodent models showing that stress induced hippocampal dendritic remodeling and kainic acid induced hippocampal cell loss lead to changes in MRI-based hippocampal volume [Wolf et al., 2002a; 2002b].

One approach that has provided further insight is molecular genetics. As mentioned above, several gene expression differences between normal and post-mortem schizophrenic brains have been identified. These gene expression studies build on the wealth of knowledge of the biochemical and molecular mechanisms of synaptogenesis. A core cellular and molecular pathway has been identified that describes the common stages of synapse assembly across different brain regions, cell-types, and developmental stages [reviewed in Garner et al., 2000]. The multi-step process begins with axonal growth cones or axonal filopodia searching for proper axo-dendritic, axosomatic, or axo-axonal contact sites [Schaefer and Nonet, 2001]. Many axonal attractant, repellant, cell adhesion, and other cell surface receptor molecules have been identified and shown to regulate these early stages of circuit formation [Chisholm and Tessier-Lavigne, 1999]. Many of these genes play a role in the so-called 'wiring problem' of the brain and reveal how the human genome with only 30,000 genes may encode wiring information for several billion neurons. [Clandinin and Zipursky, 2002]. As target sites are located, presynaptic maturation involves the accumulation of neurotransmitter-filled vesicles and other multiprotein complexes that form in the active zone to sort, release, and recycle neurotransmitter vesicles. The molecular machinery involved in vesicle sorting, fusion, and recycling is well studied and some of the vesicle fusion components such as SNAP25 (discussed in detail below) have been found to be under-expressed in patients with schizophrenia. On the post-synaptic side, initiation of assembly involves the clustering of NMDA receptor subunits via PDZ-domains and interactions with the PSD-95 protein, a major component of the postsynaptic density. As NMDA channels are activated, both $\mathrm{Ca}^{++}$and rho-familyGTPase dependent remodeling of the actin cytoskeleton and alterations in spine morphology (as seen in the time-lapse videos) facilitates further specialization of the post-synaptic density and optimal synaptic strength [Sabatini et al., 2002]. This core pathway of axonal contact, neurotransmitter release, assembly of the post-synaptic density, and spine morphogenesis is subject to many higher levels of feedback regulation. The cellular pathways underlying higher levels of regulation are of special interest, particularly during post-natal cognitive development when activity dependent remodeling and a 'use it or lose it' regimen guides neural network development [Cline 2001; LeVay et al., 1980]. Further details of these 
molecular pathways can be found elsewhere [Schaefer and Nonet, 2001; Garner et al., 2002].

As mentioned above, many of the proteins involved in the core pathway of synapse assembly have been shown to be differentially expressed in patients with developmental disorders. Another example of such a gene is the regulator of $G$ protein coupled signaling (RGS4) gene. This gene showed dramatically reduced expression in subjects with schizophrenia [Mirnics et al., 2000]. RGS4 is one of over 20 RGS family members acting as GTPase-activating proteins providing negative feedback regulation to postsynaptic G-protein coupled signaling. In addition to the loss of expression in schizophrenia, RGS4 was found to reside on chromosome1q21-22, a well known schizophrenia susceptibility locus [Brzustowicz et al., 2000]. This suggests that the loss of expression might be underlain, not by environmental factors, but perhaps by genetic variation unique to the affected patients. Alleleic variants of RGS4 were examined in a population-based gene association study and several polymorphisms were found to be preferentially transmitted to affected probands [Chowdari et al., 2001]. A similar example is brain derived neurotrophic factor (BDNF). Like FMRP, this gene shows increases in expression in response to neural stimulation [Rocamora et al., 1996] and influences dendritic morphology [McAllister et al., 1996]. Like RGS4, allelic variants in this gene have been associated with schizophrenia [Krebs et al., 2000] and MRI-based brain volume [Wassink et al., 1999].

Studies on RGS4 and BDNF couple two genetic techniques; that of gene expression level analysis (how abundantly the gene is expressed in individuals with the disorder) and gene-association analysis (what genetic variants are inherited by individuals with the disorder). Over the past 10 years, the vast majority of psychiatric genetic studies have focused almost exclusively on the "dopamine hypothesis" and dopaminergic genes. The recent gene expression findings mentioned above are notable in that very few, if any, genes involved in dopaminergic neurotransmission were found to be mis-expressed in schizophrenia. This suggests that synaptogenesis-related genes may be more central culprits in the origins of schizophrenia. Lewis and colleagues proposed a developmental model based on the normal post-natal trend of synaptic overproduction and pruning [Mirnics et al., 2001]. In their model, limited deficits in synaptic assembly arise in subjects who are genetically predisposed to schizophrenia. The disorder however, is not observed throughout most of development since early in life there is a trend toward exuberant synaptic overproduction. As adolescence approaches, the gradual process of synaptic pruning then may expose the primary deficits in synapse function and lead to a situation where inadequate or abnormal transmission exposes a cognitive deficit.

As a first step in pursuit of the "synaptogenesis hypothesis" and to further understand how genetic variation in genes that encode synaptic regulatory proteins might influence the development of executive function, we have examined the genetic underpinnings of executive attention in normal adult subjects. The neural networks that carry out attention are well studied and there is a wealth of data showing that executive attention is a core deficit in many psy-

\section{"... many of the proteins involved in the core pathway of synapse assembly have been shown to be differentially expressed in patients with developmental disorders."}

chiatric illnesses. For example, patients with schizophrenia exhibit difficulties in sensorimotor gating [Geyer and Braff, 1987], smooth pursuit eye-tracking [Matthysse et al., 1986], set-shifting [Pantellis et al., 1999], and working memory [Carter et al., 1998]. Children with attention-deficit/hyperactivity disorder (ADHD) exhibit abnormal performance in sustained and executive attention tasks [Swaab-Barneveld, et al., 2000; Swanson et al., 2000]. We have utilized the Attention Network Test (ANT), a behavioral assay that measures three separate aspects of attention [Fan et al., 2001], and is based on functional neuroimaging studies that have yielded evidence on neural areas involved in aspects of attention [Corbetta et al., 2000; Posner and Petersen, 1990]. Imaging data have supported the presence of three anatomical networks related to different aspect of attention. These networks carry out the functions of alerting, orienting, and executive control [Posner and Petersen, 1990; Fan et al., 2002]. Genetic studies of attention in normal adult subjects can be informative since attentional performance in normal subjects appears to be influenced by genetic factors [Cornblatt et al., 1988; Bartfai et al., 1991; Myles-Worsley and Coon, 1997; Cannon et al., 2000; Pardo et al., 2000] and because unaffected first degree relatives of schizophrenic patients often show impaired executive function [Faraone et al., 1999]. Inter-subject variability on the ANT has also been shown to be at least somewhat heritable, which makes the assay useful for candidate gene association studies on executive attention [Fan et al., 2001b].

\section{Molecular Genetic Studies on SNAP25 and its Potential Role in Executive Attention}

One candidate gene of particular interest is the SNAP25 gene. This gene, like RGS4, is differentially expressed in schizophrenia [Hemby et al., 2002]. It was originally identified as a synaptic vesicle gene that is preferentially expressed in neurons and that plays a key biochemical role in synaptic vesicle fusion [Zhao et al., 1994]. Biochemically, it participates in neurotransmitter release via the establishment of an anchor complex that facilitates vesicle fusion with presynaptic plasma membrane [Shao et al., 1997]. Developmentally, it may play a key regulatory role since selective inhibition via antisense oligonucleotides blocks cortical neurite elongation [Osen-Sand et al., 1993]. A mutant mouse, Coloboma, carrying a deletion of this gene shows high levels of hyperactivity [Wilson et al., 2000] and disruptions of dopaminergic signaling [Jones et al., 2001]. Gene association studies have related allelic variants of SNAP25 with attention deficit hyperactivity disorder (ADHD) [Brophy et al., 2002; Mill et al., 2002; Barr et al., 2000]. Although there is no formal evidence supporting a synaptogenesis deficit in ADHD, diminished brain volumes have been reported [Castellanos et al., 2002]. Because of this converging evidence, we investigate the influence of this gene on normal executive attention.

\section{METHODS}

To determine whether inter-subject variation in the SNAP25 gene correlates with inter-subject variation in executive attention as measured by the ANT, we performed a pilot gene association study. 120 normal subjects with normal or corrected to normal vision and 


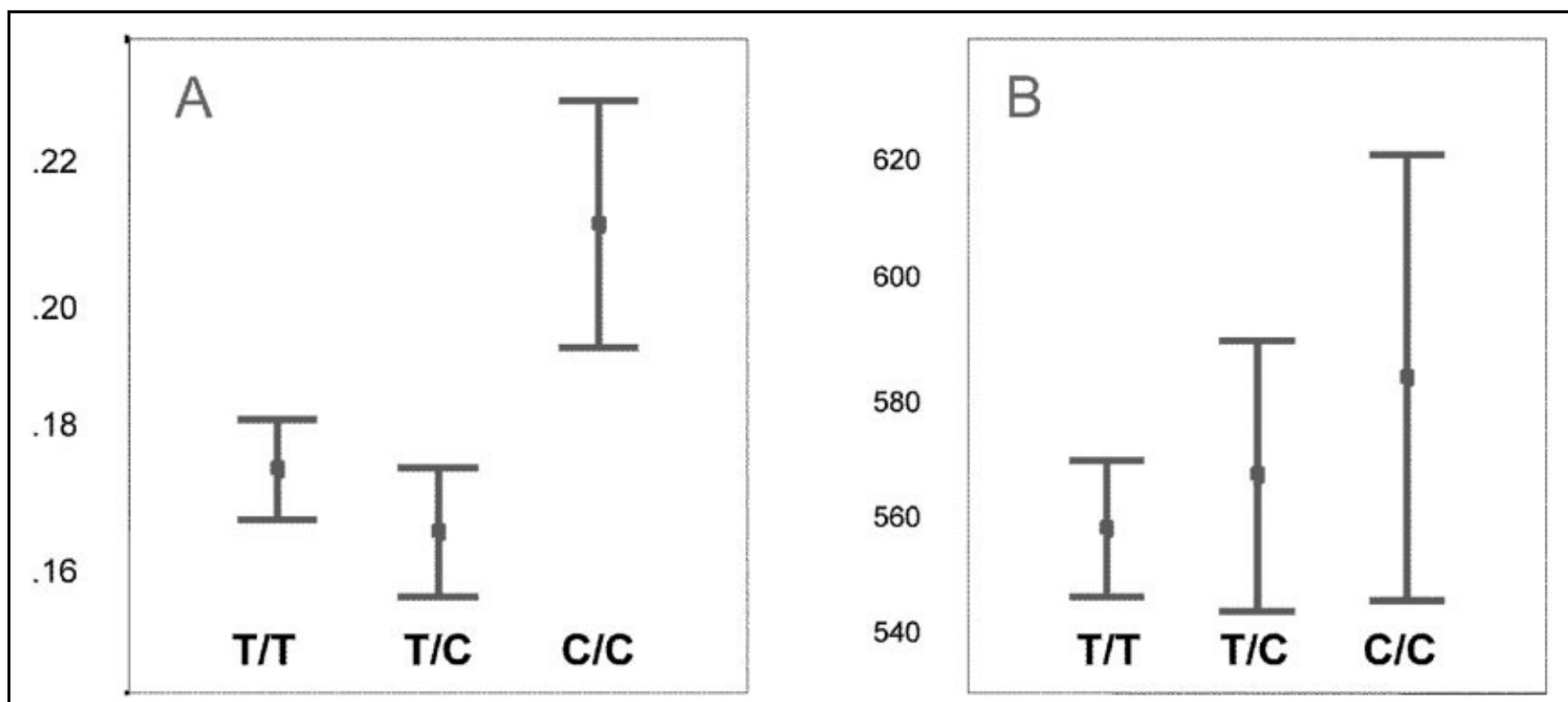

Fig. 1. Distributions (mean + SE). of SNAP25 genotypes vs. executive attention score (Fig. 1A) and overall performance (Fig. 1B). The Y-axis shows the normalized executive attention scores (Fig. 1A) and overall mean reaction time (Fig. 1B). The X-axis shows each genotypic class.

no history of psychopathology were recruited and administered the ANT as previously described [Fossella, et al., 2002]. This population is relatively small and ethnically heterogeneous and is most appropriate for the rapid analysis of quantitative data in normal subjects where promising candidate genes are known.

The ANT was performed as previously described [Fan et al., 2002]. Briefly, participants viewed the stimuli and responses were collected via two mouse buttons. Stimuli consisted of a row of five visually presented horizontal black lines, with arrowheads pointing leftward or rightward, against a gray background where the target was a leftward or rightward arrowhead at the center. This target was flanked on either side by two arrows in the same direction (congruent condition), or in the opposite direction (incongruent condition), or by lines (neutral condition).

The participants' task was to identify the direction of the centrally presented arrow by pressing one button for the left direction and a second button for the right direction. Cues consisted of a $100 \mathrm{msec}$ asterisk presented $400 \mathrm{msec}$ before the target. There were four cue conditions: (1) no-cue, participants were shown a cross which was the same as the first fixation for $100 \mathrm{~ms}$; (2) central-cue, which was at the central fixation point; (3) double-cue, in which cues were presented on the two possible target locations simultaneously (both above and below the fixation point); and (4) spatialcue, cue was presented right on the target location (either above, below the central fixation point).

A session consisted of a 24-trial practice block and three experimental blocks of trials. Each experimental block consisted of 96 trials (12 conditions: 4 warning levels $\times 2$ target locations $\times 2$ target directions $\times 3$ congruency conditions, with 2 repetitions). The presentation of trials was in a random order. Participants were instructed to focus on a centrally located fixation cross throughout the task, and to respond as fast, also as accurately as possible.

Values for attention network efficiency were calculated from the raw reaction time data as previously described. Medians were calculated for each test condition ( 4 cue levels by 3 target levels, 12 conditions in total) to avoid the influence of the outliers. The executive effect was calculated by subtracting the mean RT of congruent conditions from the mean RT of incongruent conditions. To reduce the potential confounding effect of overall RT, raw attention network scores were divided by overall RT and resulting normalized ratio scores were used in the genetic analysis seen in Figure $1 \mathrm{~A}$.

Buccal swabs were collected from consenting subjects and genomic DNA was prepared as previously described [Fossella et al., 2002]. Briefly, buccal swabs were obtained via buccal cell brush from consenting subjects and prepared as directed by the manufacturer. We used the MasterAMP Buccal Swab DNA Extraction Kit (Epicentre Technologies,
Madison, WI). Yields range from 0.5 to 3 $\mu \mathrm{g}$ of DNA from each buccal sample. Yields were determined spectrophotometrically by absorbance at $260 \mathrm{~nm}$. Taq polymerase, PCR buffer, and dNTPs were obtained from QIAGEN and used at recommended concentrations for a 20ul PCR reaction. PCR reactions and restriction digests (PCR-RFLP) were optimized and performed on the PTC100 Programmable Thermal Controller (MJ Research) outfitted with a heated lid for oil-free amplifications. A 'touchdown' PCR cycling regimen and the addition of DMSO (10\% final v:v) was used in order to automatically optimize the hybridization stringency. Gel electrophoresis in either LE agarose followed by staining in ethidium bromide was used to resolve and visualize DNA fragments. A single nucleotide ( $\mathrm{T}$ vs. $\mathrm{C}$ ) polymorphism in the non-coding region of SNAP25 gene was detected via PCR using forward primer (5'- TTCTCCTCCAAATGCTGTCG-3') and reverse (5'- CCACCGAGGAGAGAAAATG3') primers, followed by digestion with DdeI (New England Biolabs). This results in two possible bands; one at $261 \mathrm{bp}$ (T) and one at 228bp (C). After gel electrophoresis, genotypes were scored as $\mathrm{T} / \mathrm{T}$ homozygote, $\mathrm{T} / \mathrm{C}$ heterozygote or $\mathrm{C} / \mathrm{C}$ homozygote as described [Barr et al., 2000].

Following the collection of genotypes, performance data for executive attention and overall reaction time were grouped according to each genotypic class. Figure 1A shows the distribution of 
executive attention performance (incongruent - congruent) scores and Figure 1B shows the distributions of overall reaction time and executive attention scores as a function of genotype at the SNAP 25 locus. A higher score on the $\mathrm{Y}$-axis in Figure $1 \mathrm{~A}$ reflects a longer time taken in resolving conflict between stimulus and response. Subjects $(N=120)$ with the $T$ vs. C single nucleotide polymorphism genotype are plotted according to their genotype as $\mathrm{T} / \mathrm{T}$ homozygotes $(\mathrm{N}=86)$, $\mathrm{T} / \mathrm{C}$ heterozygotes $(\mathrm{N}=27)$ and $\mathrm{C} / \mathrm{C}$ homozygotes $(\mathrm{N}=7)$. As seen in Figure $1 \mathrm{~A}$, there is a nonsignificant trend toward less-efficient executive attention scores in subjects with the $\mathrm{C} / \mathrm{C}$ genotype. This type of data exemplifies the 'candidate gene association' approach where differences in the sequence of the gene are correlated with differences in a measured trait such as executive attention. As is typical of most such studies, the results below do not support a significant association between SNAP25 and executive attention, but rather show a weak trend. Power calculations show that this population $(\mathrm{N}=120)$ where one of the alleles is uncommon ('C' allele has a frequency of 0.18 ), is suitable for the detection of associations merely at the $\mathrm{P}=0.05$ level. Much larger sample sizes would be required to reach the recommended stringent $(\mathrm{P}=0.0001)$ levels. Interestingly though, as shown by comparison to Figure $1 \mathrm{~B}$, the influence of SNAP-25 seems to be somewhat specific to executive attention rather than overall performance as measured by reaction time. Studies of larger scale are required however, to establish whether SNAP25 exerts global or specific effects on processing.

\section{CONCLUSIONS}

Increases in synapse density and arborization seen in the prefrontal cortex of primates and humans seems to correlate with a relative delay in acquisition of executive attention, however, little direct evidence provides a mechanism for how synaptogenic processes influence cognitive development. While several disorders such as fragile-X mental retardation and schizophrenia show deficits in synapse formation, it is not clear how these synaptogenic deficits lead to loss of function in frontal-striatal networks. One possible line of research involves correlating genetic variation in synaptogenesis genes, with differences in executive attention. The molecular genetic approach builds on the fact that mental retardation syndromes and schizophrenia both are heritable. This approach also builds on the finding that many genes are mis- regulated in these disorders and some of the mis-regulated genes contribute to the inherited susceptibility. Here, we assessed the role of SNAP25, one candidate gene that plays a key role in presynaptic regulation of synaptogenesis. We asked whether genetic variation in this gene was correlated with variation in performance on a task that measured executive attention. The methods used here are straightforward and appropriate for further studies on candidate genes involved in synaptogenesis. The ease of high throughput genotyping should make follow-up studies on synaptogenesis related genes and executive attention relatively simple, fast, and inexpensive. While there are several limitations to the candidate gene association approach [Sullivan et al., 2001; Karmiloff-Smith et al., 2001], further integration of genetic data with MRI-based morphometry analyses and fMRI based functional analyses [methods described in detail by Kennedy et al. and Davidson et al. in this issue] may also help to better understand how the regulation of synapse formation influences the development of executive attention in humans. Durston and Eigsti and Shapiro [also in this issue] both comment on this approach in their reviews of the neurobiology of ADHD and autism, respectively.

\section{REFERENCES}

Andreasen NC, Arndt S, Swayze V, 2nd, et al. 1994. Thalamic abnormalities in schizophrenia visualized through magnetic resonance image averaging. Science 266: 294-298.

Andreasen NC, Rezai K, Alliger R, et al. 1992. Hypofrontality in neuroleptic-naive patients and in patients with chronic schizophrenia. Assessment with xenon 133 single-photon emission computed tomography and the Tower of London. Arch Gen Psychiatry 49: 943-958.

Arai Y, Ijuin T, Takenawa T, et al. 2002. Excessive expression of synaptojanin in brains with Down syndrome. Brain Dev 24: 67-72.

Barr CL, Feng Y, Wigg K, et al. 2000. Identification of DNA variants in the SNAP-25 gene and linkage study of these polymorphisms and attention-deficit hyperactivity disorder. Mol Psychiatry 5: 405-409.

Bartfai A, Pedersen NL, Asarnow RF, et al. 1991. Genetic factors for the span of apprehension test: a study of normal twins. Psychiatry Res 38:115-124.

Benes FM. 2000. Emerging principles of altered neural circuitry in schizophrenia. Brain Res Brain Res Rev 31: 251-269.

Billuart P, Bienvenu T, Ronce N, et al. 1998 Oligophrenin 1 encodes a rho-GAP protein involved in X-linked mental retardation. Pathol Biol (Paris) 46: 678.

Bonhoeffer T, Yuste R. 2002. Spine motility. Phenomenology, mechanisms, and function. Neuron 35: 1019-1027.

Brophy K, Hawi Z, Kirley A, et al. 2002. Synaptosomal-associated protein 25 (SNAP-25) and attention deficit hyperactivity disorder
(ADHD): evidence of linkage and association in the Irish population. Mol Psychiatry: 7: 913-917.

Brzustowicz LM, Hodgkinson KA, Chow EW, et al. 2000. Location of a major susceptibility locus for familial schizophrenia on chromosome 1q21-q22. Science 288: 678-682. Bartfai A, Pedersen NL, Asarnow RF, et al. 1991. Genetic factors for the span of apprehension test: a study of normal twins. Psychiatry Res 38:115-124.

Carter CS, Perlstein W, Ganguli R, et al. 1998. Functional hypofrontality and working memory dysfunction in schizophrenia. Am J Psychiatry 155:1285-1287.

Casey BJ. 2000. Disruption of inhibitory control in developmental disorders: a mechanistic model of implicated frontostriatal circuitry. In: Siegler RS, McClelland JL (eds) Mechanisms of Cognitive Development: The Carnegie Symposium on Cognition. Vol 28. Erlbaum, Hillsdale, NJ.

Castellanos FX, Lee PP, Sharp W, et al. 2002. Developmental trajectories of brain volume abnormalities in children and adolescents with attention-deficit/hyperactivity disorder. JAMA 288: 1740-1748.

Chisholm A, Tessier-Lavigne M. 1999. Conservation and divergence of axon guidance mechanisms. Curr Opin Neurobiol 9: 603-615.

Chowdari KV, Mirnics K, Semwal P, et al. 2001. Association and linkage analyses of RGS4 polymorphisms in schizophrenia. Hum Mol Genet 11: 373-1380.

Chugani HT. 1998. A critical period of brain development: studies of cerebral glucose utilization with PET. Prev Med 27:184-188.

Clandinin TR, Zipursky SL. 2002. Making connections in the fly visual system. Neuron 35: 827-841.

Cline HT. 2001. Dendritic arbor development and synaptogenesis. Curr Opin Neurobiol 11:118-126.

Conel JL. 1939-1963. The Postnatal Development of the Human Cerebral Cortex. Harvard University Press, Cambrige, MA.

Corbetta M, Kincade JM, Ollinger JM, et al. 2000. Voluntary orienting is dissociated from target detection in human posterior parietal cortex. Nat Neurosci 3:292-297.

Cornblatt BA, Risch NJ, Faris G, et al. 1988. The Continuous Performance Test, identical pairs version (CPT-IP): I. New findings about sustained attention in normal families. Psychiatry Res 26:223-238.

Davidson MC, Thomas KM, Casey BJ. 2003. Imaging the developing brain with $\mathrm{AMRI}$. Ment Retard Dev Disabil Res Rev 9:161-167.

DeFelipe, Jones. 1988. Cajal on the cerebral cortex. Oxford University Press, New York.

Diamond A. 1988. Abilities and neural mechanisms underlying $\mathrm{AB}$ performance. Child Dev 59: 523-527.

Diamond A. 1996. Evidence for the importance of dopamine for prefrontal cortex functions early in life. Philos Trans R Soc Lond B Biol Sci 351:1483-1493; discussion 1494.

Durston S. 2003. A review of the biological bases of ADHD: What have we learned from imaging studies? Ment Retard Dev Disabil Res Rev 9:000000.

Espy KA, Kaufmann PM, McDiarmid MD, Glisky ML. 1999. Executive functioning in preschool children: performance on A-not-B and other delayed response format tasks. Brain Cogn 41:178-199.

Fan J, McCandliss BD, Sommer T, et al. 2002. Testing the efficiency and independence of 
attentional networks. J Cogn Neurosci 14: 340-347.

Fan J, McCandliss BD, Sommer T, et al. 2001a. Testing the efficiency and independence of attentional networks. J Cognitive Neurosci

Fan J, Wu Y, Fossella JA, et al. 2001b. Assessing the heritability of attentional networks. BMC Neurosci 2:14.

Faraone SV, Seidman LJ, Kremen WS, et al. 1999. Neuropsychological functioning among the nonpsychotic relatives of schizophrenic patients: a 4-year follow-up study. J Abnorm Psychol 108:176-181.

Flavell JH, Feach DR, Chinsky JM. 1966. Spontaneous verbal rehearsal in a memory task as a function of age. Child Development 37:283-299.

Fossella J, Sommer T, Fan J, et al. 2002. Assessing the molecular genetics of attention networks. BMC Neurosci 3: 14

Garner CC, Nash J, Huganir RL. 2000. PDZ domains in synapse assembly and signalling. Trends Cell Biol 10:274-280.

Geyer MA, Braff DL. 1987. Startle habituation and sensorimotor gating in schizophrenia and related animal models. Schizophr Bull 13:643-668.

Giedd JN, Snell JW, Lange N, et al. 1996. Quantitative magnetic resonance imaging of human brain develoopment: ages 4-18. Cerebral Cortex 6:551-560.

Glantz LA, Lewis DA. 2000. Decreased dendritic spine density on prefrontal cortical pyramidal neurons in schizophrenia. Arch Gen Psychiatry 57: 65-73.

Goldman-Rakic PS. 1981. Prenatal formation of cortical input and development of cytoarchitectonic compartments in the neostriatum of the rhesus monkey. J Neurosci 1:721-735.

Goldman-Rakic PS, Selemon LD. 1997. Functional and anatomical aspects of prefrontal pathology in schizophrenia. Schizophr Bull 23:437-458

Hagerman RJ. 1997. Fragile X syndrome. Molecular and clinical insights and treatment issues. West J Med 166:129-137.

Hakak Y, Walker JR, Li C, et al. 2001. Genomewide expression analysis reveals dysregulation of myelination- related genes in chronic schizophrenia. Proc Natl Acad Sci U S A 98: 4746-4751.

Hemby SE, Ginsberg SD, Brunk B, et al. 2002. Gene expression profile for schizophrenia: discrete neuron transcription patterns in the entorhinal cortex. Arch Gen Psychiatry 59: 631-640

Huttenlocher PR. 1979. Synaptic density in human frontal cortex - developmental changes and effects of aging. Brain Research 163:195-205.

Huttenlocher PR, de Courten C, Garey LJ, Van der Loos H. 1982. Synaptogenesis in human visual cortex-evidence for synapse elimination during normal development. Neurosci Lett 33:247-252.

Irwin SA, Galvez R, Greenough WT. 2000. Dendritic spine structural anomalies in fragile-X mental retardation syndrome. Cereb Cortex 10: $1038-1044$

Jones MD, Williams ME, Hess EJ. 2001. Abnormal presynaptic catecholamine regulation in a hyperactive SNAP-25- deficient mouse mutant. Pharmacol Biochem Behav 68: 669676

Karmiloff-Smith A, Scerif G, Thomas M. 2002. Different approaches to relating genotype to phenotype in developmental disorders. Dev Psychobiol 40: 311-322.

Kennedy DN, Haselgrove C, McInerney S. 2003. MRI-based morphometric of typical and atypical brain development. Ment Retard Dev Disabil Res Rev 9:155-160.
Kooy RF, D’Hooge R, Reyniers E, et al. 1996. Transgenic mouse model for the fragile $\mathrm{X}$ syndrome. Am J Med Genet 64: 241-245.

Krebs MO, Guillin O, Bourdell MC, et al. 2000 Brain derived neurotrophic factor (BDNF) gene variants association with age at onset and therapeutic response in schizophrenia. Mol Psychiatry 5: 558-562.

Lendvai B, Stern EA, Chen B, et al. 2000. Experience-dependent plasticity of dendritic spines in the developing rat barrel cortex in vivo. Nature 404: 876-881.

LeVay S, Wiesel TN, Hubel DH. 1980. The development of ocular dominance columns in normal and visually deprived monkeys. J Comp Neurol 191:1-51.

Lidow MS, Goldman-Rakic PS, Gallager DW, et al. 1991. Distribution of dopaminergic receptors in the primate cerebral cortex: quantitative autoradiographic analysis using [3H]raclopride, $[3 \mathrm{H}]$ spiperone and $[3 \mathrm{H}] \mathrm{SCH} 23390$. Neuroscience 40: 657-671.

Matthysse S, Holzman PS, Lange K. 1986. The genetic transmission of schizophrenia: application of Mendelian latent structure analysis to eye tracking dysfunctions in schizophrenia and affective disorder. J Psychiatr Res 20:57-67.

McAllister AK, Katz LC, Lo DC. 1996. Neurotrophin regulation of cortical dendritic growth requires activity. Neuron 17: 1057-1064.

Mill J, Curran S, Kent L, et al. 2002. Association study of a SNAP-25 microsatellite and attention deficit hyperactivity disorder. Am J Med Genet 114: 269-271.

Mirnics K, Middleton FA, Lewis DA, et al. 2001. Analysis of complex brain disorders with gene expression microarrays: schizophrenia as a disease of the synapse. Trends Neurosci 24: 479-486

Mirnics K, Middleton FA, Marquez A, et al. 2000. Molecular characterization of schizophrenia viewed by microarray analysis of gene expression in prefrontal cortex. Neuron 28: 53-67.

Myles-Worsley M, Coon H. 1997. Genetic and developmental factors in spontaneous selective attention: a study of normal twins. Psychiatry Res 71:163-174. Cannon TD, Huttunen MO, Lonnqvist J, et al. 2000. The inheritance of neuropsychological dysfunction in twins discordant for schizophrenia Am J Hum Genet 67:369-382.

Nicola SM, Surmeier J, Malenka RC. 2000. Dopaminergic modulation of neuronal excitability in the striatum and nucleus accumbens. Annu Rev Neurosci 23: 185-215.

Osen-Sand A, Catsicas M, Staple JK, et al. 1993. Inhibition of axonal growth by SNAP-25 antisense oligonucleotides in vitro and in vivo. Nature 364: 445-448.

Pantelis C, Barber FZ, Barnes TR, et al. 1999 Comparison of set-shifting ability in patients with chronic schizophrenia and frontal lobe damage. Schizophr Res 37:251-270.

Pardo PJ, Knesevich MA, Vogler GP, et al. 2000. Genetic and state variables of neurocognitive dysfunction in schizophrenia: a twin study Schizophr Bull 26:459-477.

Park S, Holzman PS. 1992. Schizophrenics show spatial working memory deficits. Arch Gen Psychiatry 49: 975-982.

Posner MI, Petersen SE. 1990. The attention system of the human brain. Annu Rev Neurosci 13:25-42.

Rocamora N, Welker E, Pascual M, et al. 1996. Upregulation of BDNF mRNA expression in the barrel cortex of adult mice after sensory stimulation. J Neurosci 16: 4411-4419.

Rosenberg DR, Lewis DA. 1995. Postnatal maturation of the dopaminergic innervation of monkey prefrontal and motor cortices: a tyrosine hydroxylase immunohistochemical analysis. J Comp Neurol 358: 383-400.

Sabatini BL, Oertner TG, Svoboda K. 2002. The life cycle of $\mathrm{Ca}(2+)$ ions in dendritic spines. Neuron 33: 439-452.

Schaefer AM, Nonet ML. 2001. Cellular and molecular insights into presynaptic assembly. Curr Opin Neurobiol 11: 127-134.

Shao X, Li C, Fernandez I, et al. 1997. Synaptotagmin-syntaxin interaction: the $\mathrm{C} 2$ domain as a $\mathrm{Ca} 2+$-dependent electrostatic switch. Neuron 18: 133-142.

Sullivan PF, Eaves LJ, Kendler KS, et al. 2001. Genetic case-control association studies in neuropsychiatry. Arch Gen Psychiatry 58: 1015-1024.

Swaab-Barneveld H, de Sonneville L, Cohen-Kettenis $\mathrm{P}$, et al. 2000. Visual sustained attention in a child psychiatric population. J Am Acad Child Adolesc Psychiatry 39:651-659.

Swanson J, Oosterlaan J, Murias M, et al. 2000. Attention deficit/hyperactivity disorder children with a 7-repeat allele of the dopamine receptor D4 gene have extreme behavior but normal performance on critical neuropsychological tests of attention. Proc Natl Acad Sci U S A 97:4754-4759.

Thompson PM, Cannon TD, Narr KL, et al. 2001. Genetic influences on brain structure. Nat Neurosci 4:1253-1258.

Trachtenberg JT, Chen BE, Knott GW, et al. 2002. Long-term in vivo imaging of experiencedependent synaptic plasticity in adult cortex. Nature 420: 788-794

Vawter M, Crook J, Hyde T, et al. 2002. Microarray analysis of gene expression in the prefrontal cortex in schizophrenia: a preliminary study. Schizophr Res 58: 11.

Wassink TH, Nelson JJ, Crowe RR, et al. 1999. Heritability of BDNF alleles and their effect on brain morphology in schizophrenia. Am J Med Genet 88: 724-728.

Weiler IJ, Irwin SA, Klintsova AY, et al. 1997. Fragile $\mathrm{X}$ mental retardation protein is translated near synapses in response to neurotransmitter activation. Proc Natl Acad Sci U S A 94: 5395-5400.

Weinberger DR, Berman KF, Zec RF. 1986. Physiologic dysfunction of dorsolateral prefrontal cortex in schizophrenia. I. Regional cerebral blood flow evidence. Arch Gen Psychiatry 43: 114-124.

Wilson MC. 2000. Coloboma mouse mutant as an animal model of hyperkinesis and attention deficit hyperactivity disorder. Neurosci Biobehav Rev 24: 51-57.

Wisniewski KE, Segan SM, Miezejeski CM, et al. 1991. The $\operatorname{Fra}(\mathrm{X})$ syndrome: neurological, electrophysiological, and neuropathological abnormalities. Am J Med Genet 38:476-480.

Wolf OT, Dyakin V, Patel A, et al. 2002a. Volumetric structural magnetic resonance imaging (MRI) of the rat hippocampus following kainic acid (KA) treatment. Brain Res 934:87-96.

Wolf OT, Dyakin V, Vadasz C, et al. 2002b. Volumetric measurement of the hippocampus, the anterior cingulate cortex, and the retrosplenial granular cortex of the rat using structural MRI. Brain Res Brain Res Protoc 10:41-46.

Young KA, Manaye KF, Liang C, et al. 2000. Reduced number of mediodorsal and anterior thalamic neurons in schizophrenia. Biol Psychiatry 47:944-953.

Zhao N, Hashida H, Takahashi N, et al. 1994 Cloning and sequence analysis of the human SNAP25 cDNA. Gene 145: 313-314. 